\title{
Incidence Profile of Leukemias, Lymphomas, Central Nervous System Tumors and Soft-Tissue Sarcomas in Children and Adolescents in a Brazilian City
}

\author{
Jane Kelly Oliveira Friestino", \\ Priscila Maria Stolses Bergamo Francisco", \\ Djalma de Carvalho Moreira Filho ${ }^{1}$
}

\author{
1 Departament of Collective Health. \\ School of Medicine, University of \\ Campinas, UNICAMP, Campinas, Brasil.
}

\section{Contact information:}

Jane Kelly Oliveira Friestino.

Address: R. Vital Brasil n.100, 3 piso, Cidade Universitária Zeferino Vaz. Campinas SP, 13.083-970, Brasil.

” janefriestino@gmail.com
Methods: This is an epidemiological study with data from medical records between 1996 and 2005, using the form of Population-based Cancer Registry of Campinas-SP, Brazil. Differences were identified among the groups and the spatial cluster analysis was conducted.

Results: The Leukemia cases were more representative (50\%) than the others, followed by Lymphomas (22\%), CNS (21\%) and Soft Tissue $(7 \%)$. In terms of sociodemographic variables, gender $(p=0.03)$ and age $(p<0.01)$ were significantly associated with cancer in the study groups. According to the spatial distribution of the cases, the Health Districts had a non-homogeneous distribution.

Conclusions: The distribution and characteristics of the diagnoses of the study groups were similar to the results of other studies on the subject. The incidence profile can help increase awareness of the occurrences and improve the healthcare planning. 


\section{Introduction}

The cancer that affect children and adolescents are considered important, although they occur in lower frequency, when compared to the malignant neoplasms in adults [1-3]. In Latin America and in the Caribbean, they correspond to $0.5 \%$ to $3 \%$ of all malignant neoplasms, and, in Brazil, this ratio is approximately 2\% [3-7].

The risk factors and the occurrence of tumors differ among children and adults, as regards frequency and histologic type [2]. The characteristics of the childhood cancer are specific, with predominance of tumors of the hematopoietic system, Central Nervous System, supporting tissues and embryonic tissues, while, in adults, other cellular types are more prevalent, such as epithelial cell $[8,9]$.

Thus, childhood cancer has specific morphologies and some types of neoplasms can occur in different topographies. One of the measures used to systematize the information on childhood cancer is the use of a specific rating for neoplasms, based on the morphologic composition, unlike adults, who are classified according to the tumor's primary origin location $[10,11]$.

Therefore, the childhood cancer are classified in 12 diagnostic groups, known in Brazil as International Childhood Cancer Classification (ICCC), defined by the histologic type [12]. The groups are: I. Leukemias myeloproliferative diseases, and myelodysplastic diseases; II. Lymphomas and reticuloendothelial neoplasms; III. CNS and miscellaneous intracranial and intraspinal neoplasms; IV. Neuroblastoma and other peripheral nervous cell tumors; V. Retinoblastoma; VI. Renal tumors; VII. Hepatic tumors; VIII. Malignant bone tumors; IX. Soft tissue and other extraosseous sarcomas; $X$. Germ cells trophoblastic tumors, and neoplasms of gonads; XI. Other malignant epithelial neoplasms and malignant melanomas; XII. Other and unspecified malignant neoplasms. Also, this classification uses information on morphological and topographical codes already described by the In- ternational Classification of Diseases for Oncology (ICD-O) [13].

In Brazil, the information on the disease incidence is provided through the Population-based Cancer Registries (PBCR), and, according to the last publication by the National Cancer Institute -Child and adolescent cancer in Brazil: data from the population-based and mortality registry-2008, only twenty of these Registries have contributed with data related to the epidemiology of childhood neoplasms [5]. In this publication, as regards ICCC groups, the most prevalent were identified as: Group I, Group II, Group III and Group IX [5].

Little is known about the magnitude of the disease, as well as about the characteristics of the population affected, and, thus, it is necessary to use efforts to systematize and rate the information regarding cancer in the infant universe [5]. Epidemiological studies on children and adolescents diagnosed with cancer are little described by the literature, however, they are important to characterize the patient population, useful to assess the availability of healthcare service network and help in the planning of the services, adapting them to the actual needs.

Considering the above, the purpose of this study was to identify the profile of incidence of the four main types of childhood neoplasms, which are: Group I. Leukemias, myeloproliferative diseases, and myelodysplastic diseases, Group II. Lymphomas and reticuloendothelial neoplasms, Group III. CNS and miscellaneous intracranial and intraspinal neoplasms and Group IX. Soft tissue and other extraosseous sarcomas, in children and adolescents (aged $\leq 19$ ) living in Campinas, São Paulo, Brazil.

\section{Methods}

This is an epidemiological descriptive study based on the retrospective analysis of registries from the PBCR-Campinas of children and adolescents (aged $\leq 19)$ with malignant tumors seen in a High Com- 
plexity Oncology Service Unit (UNACON), exclusive for pediatric oncology.

The study was conducted in the city of Campinas, which is located in the Central-West region of the State of São Paulo, and the according to the 2000 Population Census, the Campinas population was 969,386 with population density (inhabitants $/ \mathrm{km}^{2}$ ) of 1.372.31. Its population is concentrated in the age groups between 20 and 49, with a percentage of individuals under 19 of $28 \%$ [15]. The city is divided by the City Health Department is the delimitation of Health Districts (HD), which are: North, South, East, Northwest and Southwest.

For the study, the following inclusion criteria were used: age equal or lower than 19 in the year of diagnosis, based on the age at the first consultation between 1996 and 2005; diagnoses of malignant neoplasms in Group I. Leukemias, myeloproliferative diseases, and myelodysplastic diseases, Group II. Lymphomas and reticuloendothelial neoplasms, Group III. CNS and miscellaneous intracranial and intraspinal neoplasms and Group IX. Soft tissue and other extraosseous sarcomas from ICCC; resident in the Campinas at the diagnosis moment. Cases of tumors classified as benign or undetermined were excluded.

The following variables were considered in the study:

- Sociodemographic: age, gender, color and address;

- Neoplasms-related: diagnosis, death and its primary cause.

The incidence coefficients were calculated for the study cases, using the HD divisions and their population composition according to the 2000 Census as the territorial base [15]. Standardized incidence ratios by municipality were calculated using the direct method, with the regional number of cases in the study time-frame as the standard [16].

The analyses were conducted through descriptive statistics. For the continuous variables, central tendency and dispersion measures were used. The categorical, or qualitative, variables were described with absolute and relative frequencies. The comparisons among the groups were performed by the chi-square test or generalized Fisher's exact test with $5 \%$ significance level. The data analyses were conducted in the SPSS 21.0 software.

For the spatial analyses of the data, it was necessary to perform special codifications for the variable address, according to the geographical coordinates for each home obtained for each address or only the postal code converted into the geographical projection system, latitude and longitude, UTM 23 and DATUM SAD 69 projection, using Google Earth.

As an analysis plan, we adopted the territorial delimitation by HD and the respective area of influence of the Health Centers, and we used the Kernel estimation spatial statistic for the date, allowing the elaboration of thematic maps to assess the events distribution $[17,18]$. The maps were created using the software Terraview 4.2.0.

The study was approved by the Ethics Committee of the Children's Center of Hematologic Investigations Dr. Domingos A. Boldrini (protocol 006-11).

\section{Results}

According to the inclusion criteria, a list containing 235 cases of patients throughout the study period was generated, however, only 180 were considered eligible. Since, when analyzed, some of them showed inconsistencies between the patient's home address and the city of registration. Of these inconsistencies, 23 were due to typing errors in the registration, especially between the years 1996 and 2000, and the other 32 cases because they were currently living in Campinas, but lived in other locations upon their registration.

Of the 180 cases, an average of 18 cases were observed per year, and the greatest amount occurred in 2000 (28 cases) and the lowest in 1996 (05 cases). Throughout the study period (1996-2005), there was an increase in the number of consulta- 
tions (Figure 1), and the incidence estimate for the specific groups considered in the study, based on the population of the year 2000 , was $68 / 1,000,000$ in individuals less than 19 years old.

Figure 1: Absolute frequency of cancer cases from Group I: Leukemias; Group II: Lymphomas; Group: III CNS and Group IX: Softtissues Sarcomas. Individuals under 19 years of age. Campinas. Brazil.

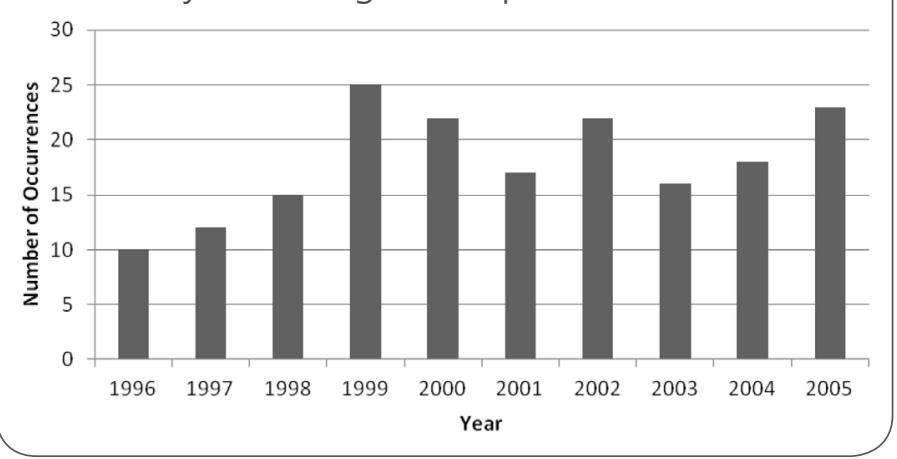

Table 1. Socio-demographic characteristics of individuals under 19 years of age, with malignant neoplasms. Campinas. Brazil..

\begin{tabular}{|c|c|c|c|c|c|c|c|}
\hline \multirow{2}{*}{ Variables } & \multicolumn{2}{|c|}{ Total } & \multicolumn{2}{|c|}{ Male } & \multicolumn{2}{|c|}{ Female } & \multirow{2}{*}{$\begin{array}{c}\mathrm{P} \\
\text { value* }\end{array}$} \\
\hline & $n$ & $\%$ & $n$ & $\%$ & $n$ & $\%$ & \\
\hline Total & 180 & 100.0 & 105 & 58.3 & 75 & 41.7 & - \\
\hline \multicolumn{8}{|l|}{ Age groups } \\
\hline 0 to 5 & 67 & 37.2 & 43 & 64.2 & 24 & 35.8 & \multirow{3}{*}{0.454} \\
\hline 6 to 11 & 57 & 31.7 & 32 & 56.1 & 25 & 43.8 & \\
\hline 12 to 19 & 56 & 31.1 & 30 & 53.6 & 26 & 46.4 & \\
\hline \multicolumn{8}{|l|}{ Ethnicity } \\
\hline White & 143 & 80.3 & 81 & 56.6 & 62 & 43.4 & \multirow{2}{*}{0.505} \\
\hline Non-White & 35 & 19.7 & 22 & 62.9 & 13 & 37.1 & \\
\hline \multicolumn{8}{|l|}{ Diagnosis } \\
\hline $\begin{array}{l}\text { Group I: } \\
\text { Leukemias }\end{array}$ & 90 & 50.0 & 51 & 56.7 & 39 & 43.3 & \multirow{4}{*}{$0.029 * *$} \\
\hline $\begin{array}{l}\text { Group II: } \\
\text { Lymphomas }\end{array}$ & 39 & 21.7 & 29 & 74.4 & 10 & 25.6 & \\
\hline $\begin{array}{l}\text { Group III: } \\
\text { CNS }\end{array}$ & 38 & 21.1 & 16 & 42.1 & 22 & 57.9 & \\
\hline $\begin{array}{l}\text { Group IX: } \\
\text { Soft-tissue } \\
\text { Sarcomas }\end{array}$ & 13 & 7.2 & 9 & 69.2 & 4 & 30.8 & \\
\hline
\end{tabular}

$\mathrm{n}$ : total number of individuals; * P-value Pearson's chisquare test; ** Fisher's test $\mathrm{p}$-value widespread.
The greatest representativeness of the cases was observed for Group I: Leukemias (50\%), followed by Groups II: Lymphomas (22\%), III: CNS (21\%) and IX: Soft Tissue Sarcomas (7\%) (Table 1).

It was verified that $58.3 \%$ of the cases corresponded to male children and adolescents. As regards the skin color, $80.0 \%$ of the children/adolescents were white, and these were the majority in all four ICCC (Table 1).

The distribution of the cases according to specific groups and patient gender showed a statisticaIly significant difference $(p=0.029)$, denoting more vulnerability among the male children/adolescents. Higher percentages of cases for the male gender were observed in Groups II, I and IX, respectively, while Group III, showed 57.8\% (IC95\%: 42.1 - 72.1) of the cases for the female gender (Table 1).

In the diagnostic groups analysis according to age, it was verified that they have specific morphologic aspects, and, in the childhood and adolescence stages, there is a characteristic and expected incidence profile. In the age group between 0 and 5 years, the highest occurrence was in Group I (58\%), followed by Groups II (16\%), Group III (14\%) and Group IX (12\%), while for the 6-11 group age, the emphasis in on Group I (47.7\%), Group III (36.4\%), Group II (11.4\%) and Group IX (4.5\%). For those aged 1219 , the distribution of the cases, according to the type of neoplasms, was: Group I (41.1\%), followed by Groups II (39.3\%), Group III (12.5\%) and Group IX (7.1\%).

The lethality rate in the study population was $37 \%$ of the total. According to the lethality rates per Group, the highest representativeness was observed in Group IX where 61\% of those diagnosed had death as the outcome (Figure 2).

Considering the georeferencing of the individuals upon their first visit to the institution, we were able to observe, by the spatialization of these occurrences, the geographical location of the cases in the city of Campinas, according to the influence area of the Healthcare Centers and Health District (HD). 
Figure 2: Number of deaths and mortality rates from Group I: Leukemias; Group II: Lymphomas; Group III: CNS and Group IX: Soft-tissues Sarcomas. Individuals under 19 years of age. Campinas. Brazil.

IX

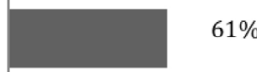

III

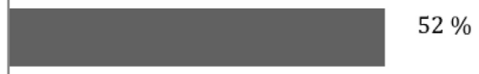

II

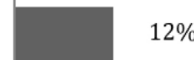

I

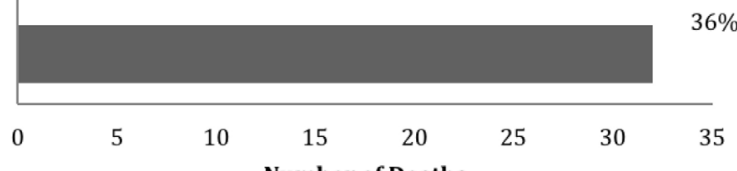

Number of Deaths
Figure 3: Spatial distribution of residence of children with cancer from Group I: Leukemias; Group II: Lymphomas; Group III: CNS and Group IX: Soft tissues Sarcomas. Individuals under 19 years of age. Campinas. Brazil.

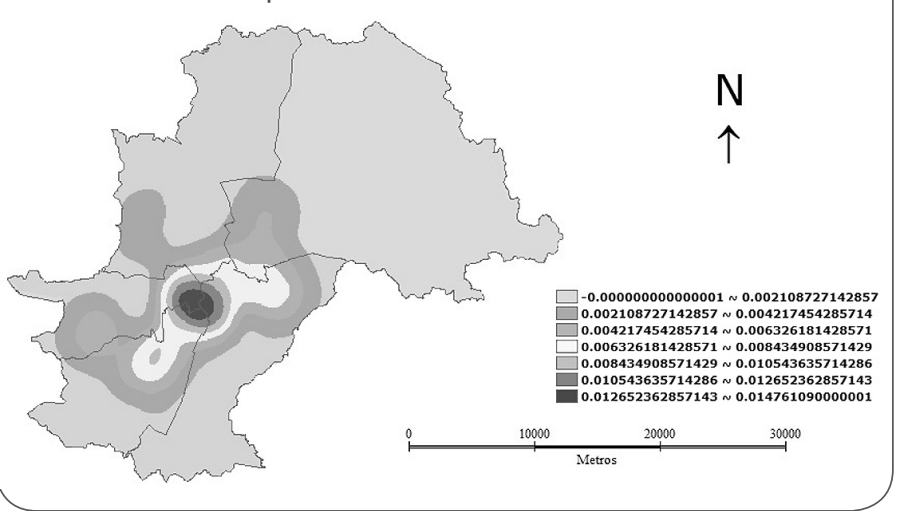

Figure 3: Spatial distribution of residence of children with cancer from a: Group I: Leukemias; b: Group II: Lymphomas; c: Group III: CNS and d: Group IX: Soft tissues Sarcomas. Individuals under 19 years of age. Campinas. Brazil.
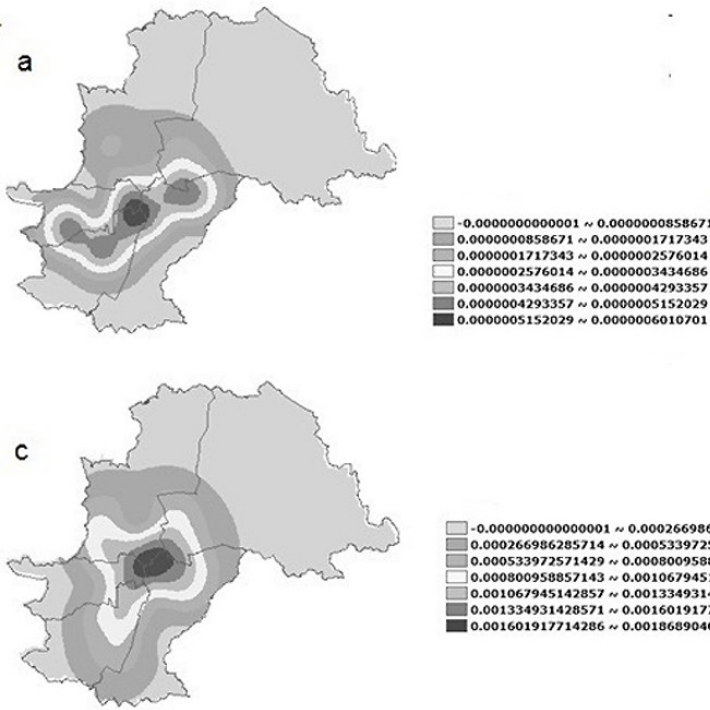
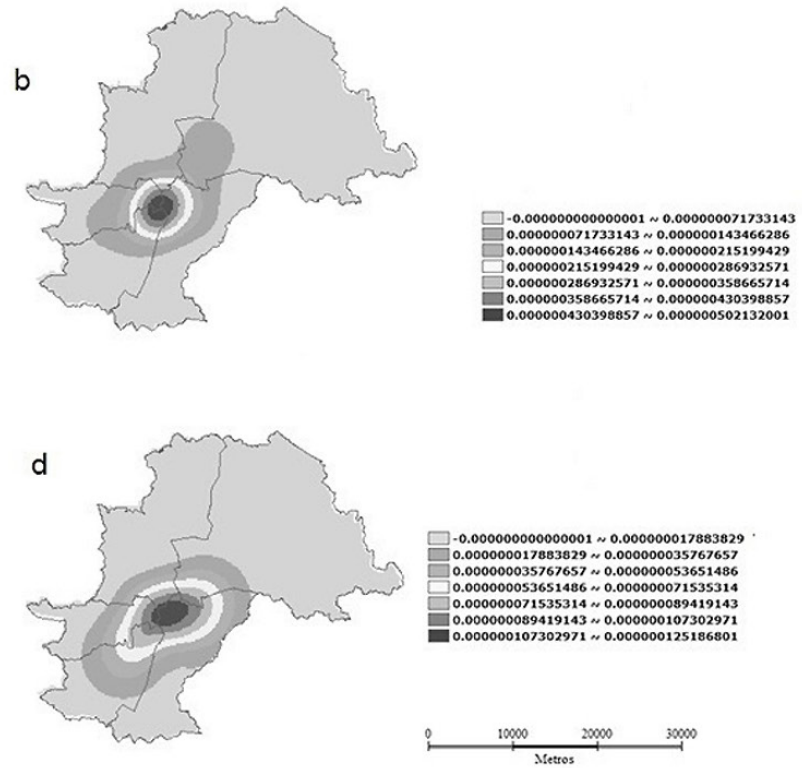

$\mathrm{N}$
$\uparrow$

* Legend shows the values of Kernelestimation
Through the Kernel estimator, a map was generated, in which the cases concentration areas can be observed. In Figure 3, all cases are observed and, through the estimator, a higher concentration of cases is visualized in the central region of the city, corresponding to the East, Southwest and South HD.
Figure 4 shows the geographical location of the homes of the patients diagnosed with neoplasms; according to the different study Groups. In item (a) is the distribution of Group I cases and, according to the HD in the city, the highest concentration corresponds, simultaneously, to Northwest, South and Southwest. For Group II (b), we observed the 
existence of one only high concentration of origin, located in the South/Southwest of the city of Campinas. For the patients Group III (c), there was a higher concentration between the South, Southwest and Northwest regions, but, contrary to the other tumors, there was a greater uniformity of the clusters, also affecting the North and East HD. In Figure $4(d)$, regarding Group IX tumors, one cluster stands out, with greater direction towards the South HD.

Considering the age differences that can occur in the population distribution per HD, in addition to the gross incidence, we calculated the incidence adjusted by age, in order to identify the occurrence standards of the study cases, considering the geographical composition of the population living in the city of Campinas. The gross incidence rates, according to $\mathrm{HD}$, were: East $(46.37 / 1,000,000)$, Northwest $(82.98 / 1,000,000)$, North $(52.98 / 1,000,000)$, South $(64.98 / 1,000,000)$ and Southwest (41.62/1,000,000). However, when adjusted, these values were: East (54.84/1,000,000), Northwest $(56.48 / 1,000,000)$, North $(52.20 / 1,000,000)$, South $(55.95 / 1,000,000)$ and Southwest $(56.14 / 1,000,000)$.

\section{Discussion}

In the assessment of the diagnostic groups according to gender, in comparison with similar studies, the percentage of CNS tumor occurrence was contrary to the expected, with higher incidence in the male population [3-5, 19-20]. In Group II: Lymphomas, the results confirm those described in the literature, with higher occurrence in the male gender (74\%), which, according to the worldwide incidence estimates, is an expected standard [4, 19].

In Brazil, Group I subtype the Acute lymphocytic leukemia (ALL) are the most incident neoplasms, respectively, however, the distribution varied according to age, showing a higher concentration between one and four years old [6]. The findings in this study corroborate these data, because, in the 0 to 5 age group, 58\% of the occurrences were in Group I: Leukemia, and, among them, the most frequent were the ALL [21].

The variable skin color has limitations for the evidences, but it can influence the occurrence of tumors. The literature points to a higher risk for white children than non-white children, for Group I and III neoplasms, and, as a result of some genetic predispositions that may have a dominant role in the etiology of these types of neoplasms [4]. In contrast, for Group IX and some subtypes in Group II, like the Burkitt subtype, a higher risk is observed for nonwhite individuals [4]. Burkitt seems to be strongly influenced by infections, with incidence differences according to environmental and economic factors, being more frequent in developing countries and populations in need, and, according to some findings, the disease development may be associated to the infectious etiology of the Epstein-Barr virus $[12,22]$.

Although the number of pediatric cancer cases is not high, they have high mortality rates, when compared to the adult cases [23]. As regards mortality, for Group IX, the rate was 61\%, and an important factor to be considered is the Strong association between the occurrence of Soft Tissue Sarcoma and the presence of congenital anomalies, which can reduce the survival rate for this group [24]. The rhabdomyosarcomas represent approximately 50\% of all neoplasms in Group IX, and, according to a study conducted in the United States, they have an incidence of 5.3/1,000,000 children [25].

In the interpretation of the mortality indicator, possible factors that could influence the results must be considered, such as socio-economic conditions, comorbidities and the patients' nutritional status, among others [26].

The monitoring starts with the knowledge of the reality and characteristics by the experienced population, disease or worsening in question [27]. The knowledge of the profile of the incidence of can- 
cer among children and adolescents in Campinas is an important step for health planning, because the real needs in a given population can be seen. Generally, the distribution and characteristics of this study, diagnostic groups show that they are similar to the standardized incidence rates of children and adolescents found in several populations.

According to the spatial distribution, the HD had a non-homogenous distribution, with a higher concentration in the South, Southwest and Northwest regions of the city. To detect the location of origin of new cases and verify their impact according to the housing location, the coefficient of incident was used as an important indicator to define the incidence profile. Thus, it was observed that Northwest HD was the one that showed the highest concentration of cases, even when these coefficients were adjusted.

Previous studies conducted in the same period of the study cases show differences in the levels of quality of life and population health through the Life Condition Index $(\mathrm{LCl})$, which incorporates dimensions of longevity, education and income, and is an extension of the Municipal Human Development Index (MHDI). In these findings, the Northwest and Southwest HD had the worst $\mathrm{LCl}$, when compared to the other HD in the city [28].

The spatial distribution of the residence locations of the children and adolescents affected by the study neoplasms did not show to be uniform in all the city's HD. It was verified that, in the South $(55.95 / 1,000,000)$, Southwest $(56.14 / 1,000,000)$ and Northwest $(56.48 / 1,000,000)$, even with the incidences adjusted for age, there was a higher concentration than in the East $(54.84 / 1,000,000)$ and North $(52.20 / 1,000,000)$. The distribution of cases per residence location emphasizes the need for awareness, in the Primary Healthcare itself, and of encouragement to early diagnosis, as a facilitator in the service flow network. Strategies like early diagnosis and immediate proper treatment must be considered, however, the pediatric neoplasms show up in non-specific complaints, signs and signals, which can lead to a late recognition of the disease $[29,30]$. Although the PCBR-Campinas information was used, it is known that for the period only cases resident in the municipality were considered, attended by UNACON. This is a limitation of the study, however based on previous records PBCR-Campinas, this service has $85 \%$ coverage of new cases from the city. Another limitation of the study is the period investigated, since, because these are rare cases, it is even more difficult to monitor worsening, and past information was considered to outline the projections [31, 32].

The identification of the incidence profile for the main neoplasms can help in exposing the occurrences more, as well as in improving the dimensioning of the services, since knowing the distribution of cases and incidence in each HD and their respective Healthcare Centers, show better possibilities for a proper planning in healthcare actions.

\section{Acknowledgments}

The authors acknowledge the support provided by the Epidemiological Data Spatial Analyses Laboratory (Epigeo) of the FCM / UNICAMP Collective Health Department and PBCR- Campinas.

\section{References}

1. Steliarova-Foucher E; Stiller C; Kaatsch P; Berrino F; Coebergh JW; Lacour B; et al. Geographical patterns and time trends of cancer incidence and survival among children and adolescents in Europe since the 1970s (the ACCIS project): an epidemiological study. Lancet. 2004; 364(9451):2097-105.

2. Ward E; De Santis C; Robbins A; Kohler B; Jemal A. Childhood and adolescent cancer statistics; 2014. CA: A Cancer Journal for Clinicians. 2014; 64(2):83-103.

3. Kaatsch P. Epidemiology of childhood cancer. Cancer treatment reviews. 2010; 36(4):277-85

4. Bailony MR; Hararah MK; Salhab AR; Ghannam I; Abdeen Z; Ghannam J. Cancer registration and healthcare access in West Bank; Palestine: a GIS analysis of childhood cancer; 1998-2007. International journal of cancer. 2011; 129(5):1180-9.

5. INCA; Instituto Nacional do Câncer. Câncer na criança e no adolescente no Brasil: dados dos Registros de Base Populacional e de Mortalidade. Rio de Janeiro: INCA; 2008. 
6. de Camargo B; de Oliveira Santos M; Rebelo MS; de Souza Reis R; Ferman S; Noronha CP; et al. Cancer incidence among children and adolescents in Brazil: first report of 14 populationbased cancer registries. International jornal of cancer. 2010; 126(3):715-20.

7. Reis RS; Santos; M.O.; Thuler; L.C.S. Incidência de tumores pediátricos no Brasil. Revista Brasileira de Cancerologia. 2007; 53(1):10.

8. Freire AM; Braga HA; Braga AA; Rolim Neto ML. Hope and Pediatric Cancer. International Archives of Medicine. 2015; 8(61):1-6.

9. Diniz $A B$ RC; Brito NP; Conceição LS; Moreira LM. Perfil epidemiológico do câncer infantil em população atendida por uma unidade de oncologia pediátrica em Salvador-Bahia. Rev Ciênc Méd Biol 2005; 4:131-9.

10. Steliarova-Foucher E; Stiller C; Lacour B; Kaatsch P. International Classification of Childhood Cancer; third edition. Cancer. 2005; 103(7):1457-67.

11. Hung GY; Horng JL; Yen HJ; Lee CY; Lee YS. Geographic Variation in Cancer Incidence among Children and Adolescents in Taiwan (1995-2009). PLoS One. 2015; 10(7):e0133051.

12. Stiller CA; Parkin DM. Geographic and ethnic variations in the incidence of childhood cancer. British medical bulletin. 1996; 52(4):682-703.

13. Fritz APC; Jack A; Shanmugarathan S; Sobin L; Parkin DM; Whelan S. International Classification of Diseases for Oncology - ICD-O-3. World Health Organization ed. 3rd; editor. Geneva 2000.

14. INCA; Instituto Nacional do Câncer. Atlas da Mortalidade por Câncer no Brasil 1979-1999. Rio de Janeiro: INCA; 2002.

15. IBGE; Instituto Brasileiro de Geografia e Estatística. Cidades @ Campinas - SP; [Internet]. 2000 [updated 2015 Nov 01; cited 2016 May 05]. Available from: http://cidades.ibge.gov. br/xtras/perfil.php?lang $=\&$ codmun $=350950 \&$ search $=$ saopaulo|campinas

16. Laurenti R JM; Lebrão ML; Gotlieb SLD. Estatísticas de Saúde. 3. ed. São Paulo: E.P.U.; 2005

17. Bailey TC. Interactive Spatial Data Analysis Malaysia: Longman Scientific \&Technical 1995.

18. Martines WRV; Machado AL; Colvero LA. A cartografia como inovação metodológica na pesquisa em saúde. Rev Tempus Actas Saúde Col. 2013; 7(2): 203-211.

19. Gatta G; Botta L; Rossi S; Aareleid T; Bielska-Lasota M; Clavel J; et al. Childhood cancer survival in Europe 1999-2007: results of EUROCARE-5-a population-based study. The Lancet Oncology. 2014; 15(1):35-47.20.
20. Araújo OL; Trindade KM; Trompieri NM; Fontenele JB; Felix FH. Analysis of survival and prognostic factors of pediatric patients with brain tumor. Jornal de pediatria. 2011; 87(5):425-32.

21. Leite EP; Muniz MTC; Azevedo ACAC; Souto FR; Maia ACL; Godim CMF et al. Fatores prognósticos em crianças e adolescentes com Leucemia Linfóide Aguda. Rev Bras Saude Mater Infant 2007; 7(4):413-21.

22. Pedrosa MF; Pedrosa F; Lins MM; Pontes Neto NT; Falbo $\mathrm{GH}$. Non-Hodgkin's lymphoma in childhood: clinical and epidemiological characteristics and survival analysis at a single center in Northeast Brazil. Jornal de pediatria. 2007; 83(6):54754.

23. Braga PE; Latorre MRDO; Curado MP. Câncer na infância: análise comparativa da incidência; mortalidade e sobrevida em Goiânia (Brasil) e outros países. Cad Saúde Pública. 2002; 18:33-44.
Publish in International Archives of Medicine

International Archives of Medicine is an open access journal publishing articles encompassing all aspects of medical science and clinical practice. IAM is considered a megajournal with independent sections on all areas of medicine. IAM is a really international journal with authors and board members from all around the world. The journal is widely indexed and classified Q1 in category Medicine. 